\title{
Reply to: Timing of Kocher maneuver in laparoscopic endoscopic cooperative surgery: Before or after endoscopic submucosal dissection?
}

We thank Ken Hagiwara and his colleagues for their comments. We agree that the complete a Kocher maneuver is efficient under some circumstances before performing endoscopic submucosal dissection (ESD).

Our standard technique for laparoscopic endoscopic cooperative surgery on duodenal tumors (D-LECS) is to stop the Kocher maneuver before ESD when the anterior wall of the duodenum is well exposed. This helps to prevent a difficult ESD due to loss of duodenal fixation on the retroperitoneum. Additional exfoliation of the posterior wall of the duodenum is done, when necessary, after ESD.

In their letter, the authors suggest changing the endoscopic view by complete Kocher maneuver before ESD to make the technique easier when it is difficult to obtain a stable view with a partial Kocher maneuver or no such maneuver. We agree that their technique would be useful in some duodenal tumors, such as tumors located at the superior or inferior duodenal angles, locations in which ESD is technically difficult to perform.
The optimal timing of completing the Kocher maneuver differs among cases of D-LECS.We recommend stopping the Kocher maneuver before ESD and checking whether ESD is feasible. Whenever ESD is not technically feasible, a Kocher maneuver should be completed before ESD.

\section{Competing interests}

The authors declare that they have no conflict of interest.

The authors

\section{Yasunori Otowa, Shingo Kanaji, Yoshihiro} Kakeji

Kobe University Graduate School of Medicine Division of Gastrointestinal Surgery,

Department of Surgery, Hyogo, Japan
Corresponding author

\section{Yasunori Otowa}

Kobe University Graduate School of Medicine

- Division of Gastrointestinal Surgery,

Department of Surgery, 7-5-2 Kusunokichou, Chuo-ku, Kobe Hyogo 6500017, Japan Fax: +81-78-382-5939

dregg338@gmail.com

\section{Bibliography}

Endosc Int Open 2022; 10: E226

DOI 10.1055/a-1722-7982

ISSN 2364-3722

(c) 2022. The Author(s).

This is an open access article published by Thieme under the terms of the Creative Commons Attribution-NonDerivativeNonCommercial License, permitting copying and reproduction so long as the original work is given appropriate credit. Contents may not be used for commercial purposes, or adapted, remixed, transformed or built upon. (https:// creativecommons.org/licenses/by-nc-nd/4.0/)

Georg Thieme Verlag KG, Rüdigerstraße 14, 70469 Stuttgart, Germany 